\title{
PROSPECTS OF DEVELOPING MEDICAL TOURISM IN INDIA
}

\author{
Binoy T $A^{*}$
}

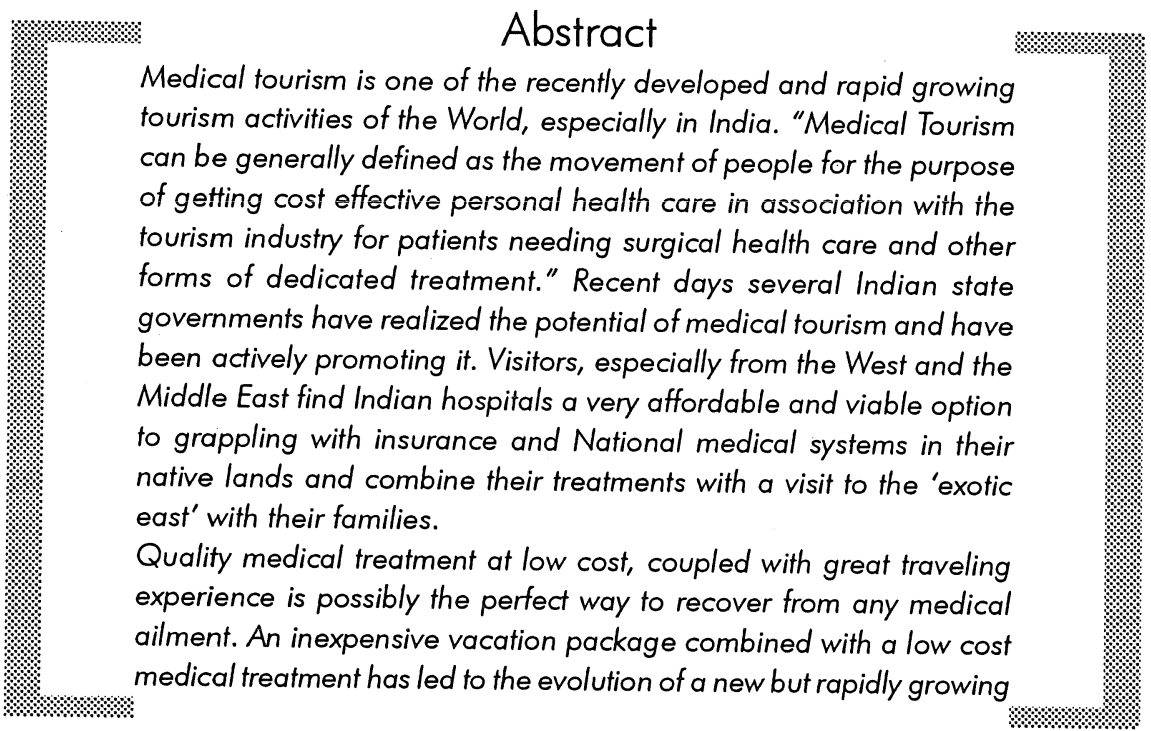
\footnotetext{
* Lecturer in Tourism Administration, Department of Tourism Administration, Kuvempu University,
Shanakaraghatta, Shimoga.
} 
industry called medical tourism. This process is being facilitated by the corporate sector concerned in heath care as well as the tourism industry including tour operators, hospital administrators, travel agents, airlines, hotels and government tourism organizations. Medical or health treatment package tourism has become a persistent form of engaging the vacation in a different way by inculcating leisure with treatment and covers a broad range of health, medical and dental services. Medical tourism is organized in such a manner that leisure time inculcate with enjoyment and recreation together with wellness and health care packages in a country other than the place of residence. Health and Medical Tourism is perceived as one of the fastest growing segments in marketing 'Destination India' today. The Ministry of Tourism, airlines, tour operators, insurance companies, tourism sector and healthcare providers can make India as a dream destination for medical Tourism through an orchestrated effort. Government and private organizations that are playing a vital role in the development of tourism in India should orchestrate their developmental efforts to take advantage of the enormous potential of Medical and Dental tourism through ensuring international standard treatment to the patients and envisage a coordinated marketing and promotional strategies enough to overcome the Asian competitors.

Tourism is recently reckoned as one of the swift developing multi-faceted service industries of India with amazing potential to generate foreign exchange earnings, employment generation and local area development. India has been placed as a demanding destination with a vast array of tourism products, which can satisfy the varying needs and wants of the guests. At the $13^{\text {th }}$ annual World Travel Awards held at Caicos Islands of Carribbean 2006, India bagged the prestigious Asia's Leading Destination Award, Asia's Leading Tourist and Convention Bureau Award and The world's Leading Travel Destination T V Commercial Award (the Incredible India campaign). A decade ago, India was merely considered as a cultural tourist destination, more than 60 percent of the tourists who had visited India for cultural attractions. However, in the present scenario the motivation behind tour to India is not only to enjoy and appreciate the year old cultural aspects but also to exploit the enormous business opportunities and to make use of the knowledge in various dimensions of science and technology. The Open Sky policy of the Government of India has brought tremendous changes in the air transportation scenario with a host of airlines launching operations in India, including international airlines, which made international and domestic air transportation easy. So while private airlines gear up to fly passengers and hotel spas prepare themselves to offer esoteric therapies, the government must roll up its sleeves to ensure this imbalance is not caused in the social sector, while 
welcoming foreign patients who bring in valuable revenue. A nice blend of topclass medical expertise at attractive prices is helping a growing number of Indian corporate hospitals lure foreign patients, including from developed nations in Europe and the America.

Indians, NRIs and tourists from around the world are beginning to realize the potential of modern and traditional Indian medicine. Indian hospitals and medical establishments have also realized the potential of this niche market and have begun to tailor their services for foreign visitors. The number of foreign patients seeking treatment in India-now 100,000-is growing by 12 percent to 15 percent a year, says the Indian Healthcare Federation. At a regional geo-political level, this nascent industry came to limelight with the arrival of 'Baby Noor' from Pakistan, who came by the Indo-Pak bus service and got a red-carpet treatment at a hospital in Bangalore. Several Indian state governments have realized the potential of this 'industry' and have been actively promoting it. Visitors, especially from the West and the Middle-East find Indian hospitals a very affordable and viable option to grappling with insurance and National medical systems in their native lands. Many prefer to combine their treatments with a visit to the 'exotic east' with their families, killing two birds with one stone.

Medical tourism is one of the recently developed and rapid growing tourism activities of the World, especially in India. "Medical Tourism can be generally defined as the movement of people for the purpose of getting cost effective personal health care in association with the tourism industry for patients needing surgical health care and other forms of dedicated treatment." Quality medical treatment at low cost, coupled with great traveling experience is possibly the perfect way to recover from any medical ailment. Medical treatment is a costly affair in developed nations that has made patients from these countries to think twice before undergoing any medical treatment in their own country. As such, they find it more beneficial to avail treatment in foreign countries offering similar and even better medical services at a far more economical cost. An inexpensive vacation package combined with a low cost medical treatment has led to the evolution of a new but rapidly growing industry called medical tourism. This process is being facilitated by the corporate sector concerned in heath care as well as the tourism industry including tour operators, hospital administrators, travel agents, airlines, hotels and government tourism organizations. Medical or health treatment package tourism has become persistent form of engaging the vacation in a different way by inculcating leisure with treatment and covers a broad range of health, medical and dental services. Medical tourism is organized in such a manner that leisure time inculcate with enjoyment and recreation together with wellness and health care packages in a country other than the place of residence. 
Health and Medical Tourism is perceived as one of the fastest growing segments in marketing 'Destination India' today. India's healthcare industry is growing at 30 per cent annually and the Apollo group alone has so far treated 95,000 international patients, many of whom are of Indian origin. While this area has so far been relatively unexplored, we now find that not only the Ministry of Tourism, Government of India, but also the various state tourism boards and even the private sector consisting of travel agents, tour operators, hotel companies and other accommodation providers are all eying health and medical tourism as a segment with tremendous potential for future growth. The driving force behind medical tourism is its cost effectiveness and the possibility of attracting substantial tourism revenue. Medical tourism in India is going up with more people from the United States, Europe and the Middle East seeking Indian hospitals as a cheap and safe alternative. India has gained acceptance in areas of medical care such as organ transplant, knee replacement, open-heart surgery and others because of the efforts of the corporate sector in the medical as well as tourism industry. The high-tech equipments and well-qualified practitioners at these hospitals are what attract patients from other countries. The death rate for coronary bypass patients at Escorts is 0.8 per cent and the infection rate is 0.3 per cent. This is well below the first-world averages of 1.2 per cent for the death rate and 1 per cent for infections. With an increasing number of foreign patients flocking to India for treatment, the country could earn Rs 100 billion (US $\$ 2.3$ billion) through 'Medical Tourism' by 2012, according to the study conducted by the Confederation of Indian Industry and McKinsey consultants. Last year approximately 150,000 foreigners visited India for treatment, with the number rising by 15 per cent a year. Medical Tourism in Kerala is booming like anything due its natural beauty with indigenous and traditional way of treatments. In 2003, the Kerala Institute of Medical Sciences (KIMS) in Thiruvananthapuram had about 450 international patients. In 2005 this figure rose to around 4,700.

Medical care, packaged with traditional therapies like yoga, meditation, ayurveda, allopathy, unani, homeopathy, naturopathy and other traditional systems of medicines, attract high-end tourists especially from European countries and the Middle East. Indian corporate hospitals excelled in cardiology and cardio thoracic surgery, joint replacement, orthopaedic surgery, gastroenterology, ophthalmology, transplants and urology to name a few. A recent outcome of the privatization of health services in India has been the growth of medical tourism to the extent that this sector is perceived as a fast-growing segment of the economy. India is a recent participant into this industry and is expected to become a $\$ 2$-billion business by 2012 . Kerala has pioneered health and medical tourism in India by branding the indigenous Arurveda inculcated with the natural beauty and other tourist attractions. But low-cost treatment is the ultimate factor weighing in favour of India. Medical care costs only one-fifth of the costs in the West. So if a particular 
surgery costs $\$ 30,000$ in the West, it would cost only $\$ 6,000$ in India. If a liver transplant costs in the range of Rs 60 lakh-70 lakh in Europe and double that in the US, a few Indian hospitals, such as Global in Hyderabad, have the wherewithal to do it in around Rs 15 lakh-20 lakh. Similarly, if a heart surgery in the US costs about Rs 20 lakh, the Chennai-headquartered Apollo Hospitals Group does it in roughly Rs 2 lakh. It is estimated that foreigners account for about 12 per cent of all patients in top hospitals of Mumbai, like Lilavati, Jaslok, Breach Candy, Bombay Hospital, Hinduja Hospital, Apollo and Wockhardt.

This promising and challenging industry should gear up the enthusiasm of the real players of tourism like tourism ministry, state tourism boards, travel agents, tour operators and hotels to utilize the great opportunity in its full extent. Health and tourism industries need to pool their resources to improve medical standards, clinical expertise, insurance coverage and appropriate infrastructure. As Indian corporate hospitals are on par, if not better than the best hospitals in Thailand, Singapore, etc there is scope for improvement, and the country may become a preferred medical destination. The Ministry of Tourism, airlines, tour operators, insurance companies, tourism sector and healthcare providers can make India as a dream destination for medical Tourism through an orchestrated effort. Mumbai, as a gateway to India, offers tremendous potential to develop medical tourism. The latest addition in Mumbai is the Asian Heart Institute at BandraKurla Complex, which offers high-tech facilities for all types of heart complications and even offers preventive cardiological treatment to avoid heart ailments and also to keep under control a host of heart problems. This institute, which is in collaboration with the Cleveland Institute, USA, offers 'five-star' services at reasonable prices. There are even provisions for financial assistance which is offered through various trusts associated with the institute. There are wide ranges of hospitals, which help to promote medical tourism in Maharastra. Some of these are Lilavati Hospital, Jaslok Hospital, Bombay Hospital, Hinduja Hospital, Wockhardt Hospital and Apollo NUSI Wellness Retreat. Hotels like Hyatt Regency, JW Marriott, Renaissance and Resort, also offer extensive spa facilities aimed at rejuvenating both the domestic and international tourist.

National Coalition on Health Care reports about 500,000 Americans traveled overseas last year to undergo surgeries that would have cost two to three times more in the United States. Medical tourism has risen in the last few years, with U.S. employer-sponsored health insurance premiums skyrocketing and average of 87 percent over the last six years As more and more patients from Europe, the US and other affluent nations with high medicare costs look for effective options, India is pitted against Thailand, Singapore and some other Asian countries, which have good hospitals, salubrious climate and tourist destinations. However, the cost effectiveness works as a boon only for a fraction of patients who can 
afford to migrate from their countries where these services are expensive. They come to countries like India, where they can afford almost the same quality of treatment but with the additional excitement of tourism. Things are going to change drastically in favour of India, especially in view of the high quality expertise of medical professionals, backed by the fast improving equipment and nursing facilities, and above all, the cost-effectiveness of the package. Instead of paying $\$ 2,00,000$ for a mitral valve surgery in the US, a patient could travel to India and receive the same treatment for $\$ 6,700$. Similarly, rather than paying 15,000 pounds Sterling for hip resurfacing in the UK, a patient can get the same procedure for 5,000 pounds in India, including surgery, airfare and hotel stay.

Only specialized hospitals run by large private corporate entities are currently able to provide medical tourism. A large influx of the well-heeled or foreign patients could lead to a reverse brain drain with government medical practitioners migrating to these affluent centers of medical excellence, to the detriment of the poor. At present, about 59 per cent of medical practitioners are located in the cities, though the bulk of India's population lives in the remote rural interiors, which any way are deprived of basic healthcare facilities. The Apollo Group, Escorts Hospitals in New Delhi and Jaslok Hospitals in Mumbai are to name a few which are established names even abroad. A list of corporate hospitals such as Global Hospitals, CARE and Dr L.V. Prasad Eye Hospitals in Hyderabad, The Hindujas in Mumbai, etc also have built capabilities and are handling a steadily increasing flow of foreign patients. India's healthcare industry is growing at 30 per cent annually and the Apollo group alone has so far treated 95,000 international patients, many of whom are of Indian origin.

Amidst varied general and specialty medical treatment packages, the noteworthy packages are,

- Health care facilities

- Joint Replacement Surgery Package

- Neuro-Surgery and Trauma Surgery treatment package

- Osteoporosis Medical Treatment Packages

- Refractive Surgery Package

- Urology

- Vascular Surgery Package

- Dental Care Medical Package

- Bone Marrow Transplant 
- Cardiac Care and Surgery Package

- Cosmetic surgery Package

- Dialysis and Kidney Transplant Package

- Gynecology and Obstetrics

\section{Dental Care \& Medical Treatment in India}

Dental care Tourism India is an up-and-coming concept for a planned holiday along with total Dental solution and care. Health care problems and treatment packages are very expensive in most of the European and American countries compared to this part of the world. India provides outstanding dental care medical package to meet up the treatment outlay and at the same time guide one to spend the vacation. One can enjoy the holidays and receive services connected to Dentistry such as Dental Implants at a very reasonable price.

Dentistry is an exuberant industry with 13,000 practicing dentists in the US whereas; in India 80,000 dentists are operating. However, at the same time it is not affordable by average citizens due to the posh Dental Care Services. Dental care treatment is usually not reimbursed by the National Health Schemes of some countries and is too classy. The disparity in charge of a Dentist from US to India is value a thought. That is why India has of late become a chief tourist focal point of Dental Care medical Solutions. In spite of low cost, the patient still gets Quality Treatment Package in India primarily due to low labor cost as compared to any other area in world. Because, savings are only significant if the patient receives Quality Treatment, equivalent to or better than that accessible in their home country.

Millions of people every year fly from USA and Europe to tourist places in India for a majestic holiday and dental treatment. The cost of dental treatment is the western countries are approximately 10 times more than that in India. Dental treatment in India is low-priced as compared to the western countries. In India, we have clinics with state to the art devices and well trained veteran doctors to match the best of international standards.

Different dental treatments offered in India are

- Smile Designing

- Metal Free Bridge

- Dental Implants 
- Porcelain Metal Bridge

- Porcelain Metal Crown

- Tooth Impactions

- Root Canal Treatments

- Tooth Whitening

- Tooth Colored Composite Filings

- Tooth Cleaning

\section{Cosmetic Treatment}

A new horizon of the medical field cropping out in India is cosmetic surgery, which utilizes some of the state of the art techniques in corrective procedures. Some disfigurations corrected include hair restoration (hair implants, hair flaps, and scalp reductions), rhinoplasties (reshaping or recon touring of the nose), stalling of the aging process (face lift, cosmetic eyelid surgery, brow lift, submetal lipectomy for double chin), demarcations (sanding of the face,) otoplasty for protruding ears, chin and cheek enlargement, lip reductions, various types of breast surgery package and reconstruction and liposuction. To be true to the ubiquitous goings on we have to admit that India is no longer a historical attraction hunch but has emerged as one of most competitive and up to date technology based solution to all medical quandaries.

Cosmetic surgery package is one of the magic that Indian medical treatment packages have shown. Primarily the elite society opts for this as it's affordable by them at ease. Use of radioactive isotopes in small doses and utilization of Gamma camera in the treatment packages have added new dimension to the medical tourism India. Foreigners are coming every year in India to get their health check ups done at a reasonable price. Non-invasive surgical events like streotactic radio surgery and radiotherapy for brain tumors are practiced productively. Medical Tourism is a new and budding concept internationally and one of the key surgeries for which patients opt for Medical Tourism is Cosmetic Surgery, and what superior place to get this done than India. Advantages include low cost, no waiting lists and a high-class holiday.

A latest report by 'The Independent' declared that over 10,000 Britons travel to India every year for stomach tucks, breast enlargements and facelifts with a convalescence beach holiday thrown in. A tummy tuck can cost up to 6,500 pounds in Britain but only 1,500 pounds abroad with a full holiday deal included 
in India. A number of orthopedic procedures are available such as hip and knee replacement, the Illizarov technique, limb lengthening, Birmingham Hip resurfacing technique (which scores over conventional hip replacements and is still unavailable even in the US) etc.

Many hospitals specialize in latest techniques and treatments such as minimal invasive surgery, cartilage and bone transplantation, spine surgery and limb sparing surgery. All kinds of muscular- skeletal problems ranging from Arthritis to sports injuries, to complex broken bones, bone tumors and childhood conditions like scoliosis are treated most effectively. A wide range of spinal surgeries including fixation, stabilization and fusion are regularly undertaken.

\section{Health Tourism in Karnataka}

Medical Tourism has been given preference in the tourism policy of the Karnataka State and the Department of Tourism, Government of Karnataka, has clear cut plans to promote Medical tourism in the state. The idea is to make Karnataka a top health tourism destination, not only in India but internationally. Karnataka wants to lure foreigners to the state to avail of sophisticated facilities and subsequently induce them to enjoy the multiple tourism offerings. This endeavour will have a positive impact on the entire economy of the state. In fact, the government is setting up a Bangalore International Health City Corporation, which will cater to patients for a wide variety of health care products and treatments.

The state also boasts of having the unique property, Golden Palms Spa \& Resort, which is the one and only resort in the country where a guest can have a complete range of pathological tests, dental treatment, electro-cardiograms, stress tests, $X$-rays, and even sonography tests. To crown it all, there is even a mini-operation theatre for cosmetic surgery performed by world-renowned surgeons in the field.

\section{Destinations for Medical Tourism in India (Major Hospitals)}

AllMS, Delhi: India Institute of Medical Sciences is located in Delhi and offers treatment in its 25 clinical department including four-specialty center. These departments are aided in their activities by the pre and para clinical departments. AllMS provide medical treatment at a relatively low cost for the benefits of patients.

Apollo Hospitals - The largest corporate Hospital outside US, Apollo hospital belongs to the prestigious Apollo Group. This multispeciality hospital holds the 
distinction of treating 60,000 patients between the period of 2001-2004. There is also an Apollo Hospital dedicated to the treatment of cancer patients.

Escorts Heart Institute and Researh Centre, Delhi - EHIRC is the leader in heart treatment in India and has three bi hospitals in Delhi, Faridabad and Amritsar. Rated as the best heart hospital of the country by Outlook- survey, the EHIRC (Delhi) provides a high standard heart care in the country supported by advanced technology. The other two hospitals are equally known for their quality patient care.

Ram Manohar Lohia Hospital, Delhi - The Ram Manohar Lohia Hospital is a super speciality hospital providing standard treatment for a long time now. Neuro Surgery, Cardiology, Bum \& Plastic Surgery are some of the speciality treatment offered in this hospital apart from the routine treatment.

Sir Ganga Ram Hospital, Delhi - Sir Ganga Ram Hospital is a super speciality hospital providing quality treatment to patients since last many decades. Due to its expertise in various fields of treatment, it has gained the respect of a large number of people.

B M Birla Heart Research Centre, Kolkata - This is a multispeciality hospital offering standard cardio vascular treatment. The hospital has special interest in the advanced field of cardiac surgery, especially re-constructive operations on infants.

Peerless Hospital and BK Roy Research Centre, Kolkata - Located amidst salubrious environments of southern Kolkata, the Peerless Hospital and BK Roy Research Centre provides quality medical services and facilities. It is a multi disciplinary and super specialty hospital.

Kothari Medical Centre \& Research Institute, Kolkata- The Kothari Medical Centre \& Research Institute has some of the best medical \& surgical healthcare services in the country. Backed by a dedicated staff and modern technology, the Kothari Medical Centre and Research Institute provides standard services to all its patients.

Jaslok Hospital \& Research Centre, Mumbai - A multi speciality hospital, the Jaslok Hospital \& Research Centre is one of the oldest trust hospitals in India. Its healthcare facilities are renowned for their good treatment and patient care.

Breach Candy Hospital, Mumbai - The Breach Candy Hospital is one of the major hospitals of Mumbai where the medical needs of the patients are taken care of with an expertise that is commendable. Its nursing care and quality 
diagnostics have earned it rave reviews from the medical professionals and patients alike.

Hinduja Hospital, Mumbai - Belonging to the Hinduja Group, the Hinduja Hospital functions in collaboration with Massachusetts General Hospital (MGH), Boston. The hospital has earned itself recognition because of its quality medical services.

Mallya Hospital, Bangalore - The Mallya Hospital holds the distinction of being the very first to be awarded the ISO-9002 certificate. It is a super speciality hospital with modern diagnostics \& treatment facilities for its patients.

Manipal Hospital, Bangalore - The Manipal Hospital managed by Asia's largest hospital management group offers treatment at a cost that is not very expensive for the common people. The modern technology and the caring staff makes sure that patients get every facility needed by them.

\section{Major Ayurveda Centres}

Kalpa Siddhi Health \& Life Care, Ahmedabad - The Kalpa Siddhi Health \& Life Care is a prominent Ayurvedic Centre in providing effective ayurveda remedies for ailing patients. This centre is based in Ahmedabad. Some of the therapies provided here include high blood pressure, cancer, anemia, over weight, high cholesterol, hypothyroid, oligospermia, diabetes, kidney problem, skin problem and other common diseases.

Gujarat Ayurvedic University, Jamnagar - This is yet another renowned ayurvedic centre in Gujarat that offers its patients a whole range of treatment. Equipped with state of art technique, this ayurveda centre is managed by a group of well-trained practitioners.

Santhitheeram Centre, Ernakulam- Situated on the banks of Vembanad Lake in Kerala, the Santhitheeram Centre is one of the best places in country to receive ayurvedic treatment. The salubrious atmosphere around fastens the recovery of the patients. Some of the most important treatments given here are Herbal Oil Massage, Steam Bath, Slimming Programs, Stress Management Programs and Beauty Care Programs.

Ausara Ayurveda, Delhi - The Ausara Ayurveda Centre is located in Delhi and offers a whole range of treatment for the benefit of its patients. The treatment provided here include anti aging skin treatment, skin care treatment, body firming 
treatment, Ayurvedic therapy, spa/salon services including cleansing \& glow facial, back purification \& polishing, rejuvenating anti stress massage, toning treatment, hand \& foot spa.

Indian Alternate Therapy Institute, Gaya - The Indian Alternate Therapy Institute is located in Bodh Gaya and offers a range of treatment for its patients. Some of the treatments that can be taken here are Ayurvedic healing, Aromatherapy, Crystal healing, Reflexology, Stress management and Reiki.

Divya Yoga Trust, Haridwar - Divya Ayurvedic Trust is located in Haridwar and claims to provide treatment for almost all types of ailments, through ancient India therapeutic treatment (Yoga \& Meditation and Ayurveda). The medicines given to the patients here are made from pure herbs of the Himalayan region.

\section{Major Yoga Centres}

Vivekananda Kendra, Bangalore - The Vivekananda Kendra was founded in the year 1972 and today, it is one of the primary destinations for yoga programmes in India. The Kendra has altogether 170 branches spread throughout the country. It provides a whole range of yoga and meditation programmes to cure the patients from certain diseases.

B.K lyengar Yoga Institute, Pune - The BK lyengar Institute of Yoga offers yogic practices developed by BK lyengar some four decades ago. The institute is located in Pune and provides effective treatment for its patients including the asana postures and pranayama in hatha-yoga.

Art of Living Foundation, Bangalore - The Art of Living Foundation is an extremely renowned yoga and meditation centre that has its branches in more than 142 countries. The centre functions under the guidance of Sri Sri Ravishankar. The yoga and meditation practices prescribed to the patients have earned fruifful results.

The Ramakrishna Mission, Kolkata - The Ramakrishna Mission was established by Swami Vivekanand with an aim to spread the teachings of Ramakrishna Paramanhas. Regular yoga and meditation classes have helped many patients to recover from their ailments.

Bihar School of Yoga, Bihar - The Bihar School of Yoga was established by Paramhansa Shivanand in the town of Munger. Yoga treatments on offer here include Yogic Sadhana, Yogic health management and Yogic stress management. 
The government and private organizations that are playing a vital role in the development of tourism in India should orchestrate their developmental efforts to take advantage of the enormous potential of Medical and Dental tourism through ensuring international standard treatment to the patients and envisage a coordinated marketing and promotional strategies enough to overcome the Asian competitors. Our indigenous medicinal systems like Ayurveda, Yoga, Meditation and Naturopathy should be more highlighted in the European and American markets and be obliged to convey trustworthiness through offering standard and transparency in treatments. While there are world-class physicians in India, the lack of appropriate sanitation and infrastructure is likely to doom India's medical tourism aspirations. The sanitation and other infrastructure problems are not addressed and soon, that potential will not likely be realized. Other countries in the region may cost more but will likely remain the primary destinations. Patients from developed countries expect a clean safe environment both in the hospital and out. The hi tech and international standard medical treatment and better payment scheme to the medical professionals may reduce the brain drain of such human resources from India to foreign countries. A portion of out bound tourist traffic from India belong to the category of medical tourism which can be minimized by providing better medical amenities and facilities in India.

\section{References}

1. India Fosters Growing Medical Tourism Sector, Ray Marcelo, The Financial Times, 2 July 2003

2. Business Line, May 10,2006 www. Google .com

3. T3 Travels Trends Today, December 2006

4. Business Line, September 3, 2004

5. Business Line, February 01, 2005

6. Kerala Tourism News Letter (on line) 